\title{
Epidemiological Characteristics of Hepatitis B Positive Patients in Oman between 2009 and 2019: A Retrospective Cohort Study
}

\begin{abstract}
Salah T Al Awaidy ${ }^{*}$, Khalid Al Naamani², Gowda Sathyanarayana ${ }^{3}$, Abdullah AlKalban², BR Kamath ${ }^{2}$, Siham Al Sinani ${ }^{3}$, Elias Said ${ }^{4}$, Heba Omer ${ }^{5}$, AlZahraa Al Mehrzi ${ }^{2}$ and Ozayr Mahomed ${ }^{6}$
\end{abstract}

${ }^{1}$ Office of Health Affairs, Ministry of Health, Muscat, Oman

${ }^{2}$ Department of Medicine, Division of Gastroenterology and Hepatology. The Armed Forces Hospital, Oman

${ }^{3}$ Oman Medical Speciality Board, Oman

${ }^{4}$ Department of Microbiology and Immunology, College of Medicine and Health Sciences, Sultan Qaboos University, Oman

${ }^{5}$ Department of Endemic Medicine and Hepatology, Faculty of Medicine, Cairo University, Egypt

${ }^{6}$ Department of Public Health Medicine, University of KwaZulu Natal, Durban, South Africa

*Corresponding author: Salah T Al Awaidy, Office of Health Affairs, Ministry of Health, Muscat, Oman, Email: salah.awaidy@gmail.com.
Received Date: July 23, 2021

Published Date: August 09, 2021

\section{Introduction}

Introduction: The prevalence of chronic hepatitis B virus (HBV) in Oman was estimated to have been 2-7\% prior to the introduction of vaccination. However, HBV remains a major concern among unvaccinated individuals, especially older adults.

Objective: The study aim is to describe the epidemiological characteristics of HBV positive patients at a specialized liver clinic at the Armed Forces Hospital, between January 2009 and December 2019. A retrospective cohort study was undertaken, and secondary data were obtained from electronic medical records.

Results: 593 patients with positive HBV serology were identified. Fifty-nine percent of patients were male, with a mean age of 42 years (SD: 10.05) compared to females (43 years, SD: 10.70). Eighty-five percent (492/580) of the patients were treatment naïve. Eighty-eight percent showed detectable HBV viremia. The median level of HBV DNA among chronic hepatitis BV patients who are HBeAg-positive was significantly higher: 1884 $847 \mathrm{IU} / \mathrm{ml}$ (IQR: 81662-486924145), as compared to the rest of chronic hepatitis BV patients: 339 IU/ml (IQR: 33.5-3366). Elevated ALT ( $\geq 40$ IU/ $\mathrm{ml}$ ) was found in $29 \%$ of the patients. liver abnormalities were detected by ultrasound in $28 \%$ (165) of patients. Treatment was introduced in $15 \%$ of patients.

Conclusion: The majority of HBV patients were seronegative for HB-Ag and were born before the vaccination era. Therefore, these patients with hepatitis B in dormancy do not need treatment, but regular monitoring and follow-up.

Keywords: HBV; Epidemiology; HBV DNA; HBe-Ag; Oman

\section{Introduction}

Viral hepatitis is a silent epidemic with serious impact on people, communities, and the overall health system. The World
Health Organisation (WHO) launched the Global Health Sector Strategy on Viral Hepatitis 2016-2021 towards the Elimination 
of HBV and provisional guidance for country validation of viral hepatitis elimination in June 2021 [1]. In 2019, an estimated 296 million persons (3.8\% of the population) were infected with the chronic hepatitis B virus (HBV) worldwide [1]. The World Health Organization (WHO) estimates the number of hepatitis B-related deaths in 2019 at 820,000 [450,000-950,000] [2]. The WHO estimates that about 3.3\% of the people from the Eastern Mediterranean Region (EMR) are infected with chronic HBV where Yemen (12.7\%-18.5\%), Sudan (5\%-8.2\%) and Somalia (5.6\%$21.3 \%$ ) are the most affected [3].

In Oman, prior to the introduction of vaccination (1989), the prevalence of chronic HBV infection was estimated at $2 \%$ to $7 \%$ [4]. Hepatitis B vaccine was administered 2, 4 and 6 months. The estimated average carrier rate for HBV was 2.5\% (2.11-2.9\%); and the number of people living with chronic HBV was modelled at $114,380(96,850$ - 32,931) [5]. A sero-prevalence study conducted in 2005 revealed that 15 years after the onset of $\mathrm{HBV}$ vaccination, chronic HBV sero-prevalence in children declined from $2.3 \%$ in 1990 to $0.5 \%$ in 2005 [6]. A study has found that HBV genotypes $\mathrm{D}$ and $\mathrm{A}$ are the most common in Oman [7]. In an earlier study, examining the characteristics of HBV infection in 154 Omani patients, for the majority of HBV-infected patients, the hepatitis $B$ e antigen ( $\mathrm{HBeAg}$ ) was negative, and the hepatitis B viral load was low [8]. In Oman, despite the introduction of HBV immunization, chronic HBV remains a serious concern in the unvaccinated and the elderly. Little is known about the current cohort of HBV patients undergoing treatment in the country's specialized liver clinic. This study is intended to describe the clinical and epidemiological features of a cohort of chronic HBV patients receiving care at a specialized liver clinic in Oman as part of HBV elimination strategy.

\section{Method}

\section{Study design and population}

This is a retrospective cohort study of all adult patients with chronic HBV infections who have been treated and followed up at the Armed Forces Hospital (AFH), Muscat, Oman, between January 2009 and December 2019. Data for all treated patients were recorded electronically and stored in the hospital database system. For the purposes of this study, only patients who have been diagnosed with chronic HBV at AFH and for which initial visit files were available and completed, were included in the study.

\section{Study setting}

The AFH is one of four tertiary hospitals in the capital city of Muscat. The hospital has a dedicated hepatology clinic, adequately equipped with all supportive equipments. This is one of three liver clinics within the country. An estimated 65 new cases of HBV are diagnosed each year. The liver clinic has a dedicated fibroscan machine and accepts patients from all governorates (provinces) of Oman.

\section{Data Collection}

Secondary data were collected from the hospital's database system. The following variables were retrieved: socio-demographic (age, gender, smoking, alcohol history), hepatitis B serology including Hepatitis B surface antigen (HBsAg) and antibody (antiHBs), Hepatitis B core antibodies (anti-HBc), Hepatitis B e antigen (HBeAg) and antibody (anti-HBe), Hepatitis B DNA (HBV DNA), and liver chemistry tests including bilirubin, albumin, transaminases (aspartate transaminase, (AST), and alanine transaminase, (ALT) and alkaline phosphatase, (ALP). Findings of ultrasound of the abdomen were also collected.

\section{Statistical analysis}

Numerical variables such as age and HBV DNA concentrations were analysed using centrally trended measurements. Categorical variables such as gender, radiological results and abnormalities in liver chemistry and hematology tests were calculated as proportions and displayed in frequency tables. Radiological results were classified as normal or reported abnormalities, liver chemistry tests and hematological tests were classified as normal or abnormal for laboratory reference ranges. A student t-test was used to identify likely differences between the mean age of men and women. Patients were classified as HBeAg positive chronic hepatitis B patients and having a high viral load with the HBV DNA levels > 20,000 IU/ml, and HBeAg negative chronic hepatitis B patients with HBV DNA levels $>2000 \mathrm{IU} / \mathrm{ml}$ [9].

\section{Ethics and permission}

Ethical approval was obtained from the Armed Forces Medical Services Ethics Committee. There was no contact with patients as the patients' identifiers were coded; as a result, no informed consent was obtained. This study abides by the ethical principles of the Helsinki Declaration.

Result

Table 1: Socio-demographic and risk profile of chronic hepatitis B virus (HBV) and ultrasound findings cohort of patients, Oman, 2009-2019.

\begin{tabular}{|c|c|c|c|}
\hline & Male, $\mathbf{n = 3 5 2}(\%)$ & Female, $\mathbf{n = 3 5 2}(\mathbf{\%})$ & Total Population, N=593 (\%) \\
\hline Gender & $352(59)$ & $241(41)$ & $593(100)$ \\
\hline Risk factors & \multicolumn{3}{|l|}{} \\
\hline Smoking & $3(0.85)$ & 0 & $3(0.51)$ \\
\hline Alcohol consumption & $6(1.7)$ & 0 & $6(1.0)$ \\
\hline Diabetes & $27(7.7)$ & $9(4.0)$ & $36(6.0)$ \\
\hline Hypertension & $21(6.0)$ & $9(4.0)$ & $30(5.0)$ \\
\hline
\end{tabular}




\begin{tabular}{|c|c|c|c|}
\hline \multicolumn{3}{|c|}{ Family history of Hepatitis B } & \multicolumn{2}{|l|}{} \\
\hline Yes & $80(23)$ & $60(25)$ & $140(24)$ \\
\hline No & $153(44)$ & $99(41)$ & $252(42)$ \\
\hline Don't know & $119(33)$ & $82(34)$ & $201(34)$ \\
\hline Family history of hepatocellular carcinoma & \multicolumn{3}{|}{} \\
\hline Yes & $7(2.0)$ & $1(0.4)$ & $8(2)$ \\
\hline No & $256(72)$ & $183(76)$ & $439(74)$ \\
\hline Don't know & $89(25)$ & $57(24)$ & $146(24)$ \\
\hline
\end{tabular}

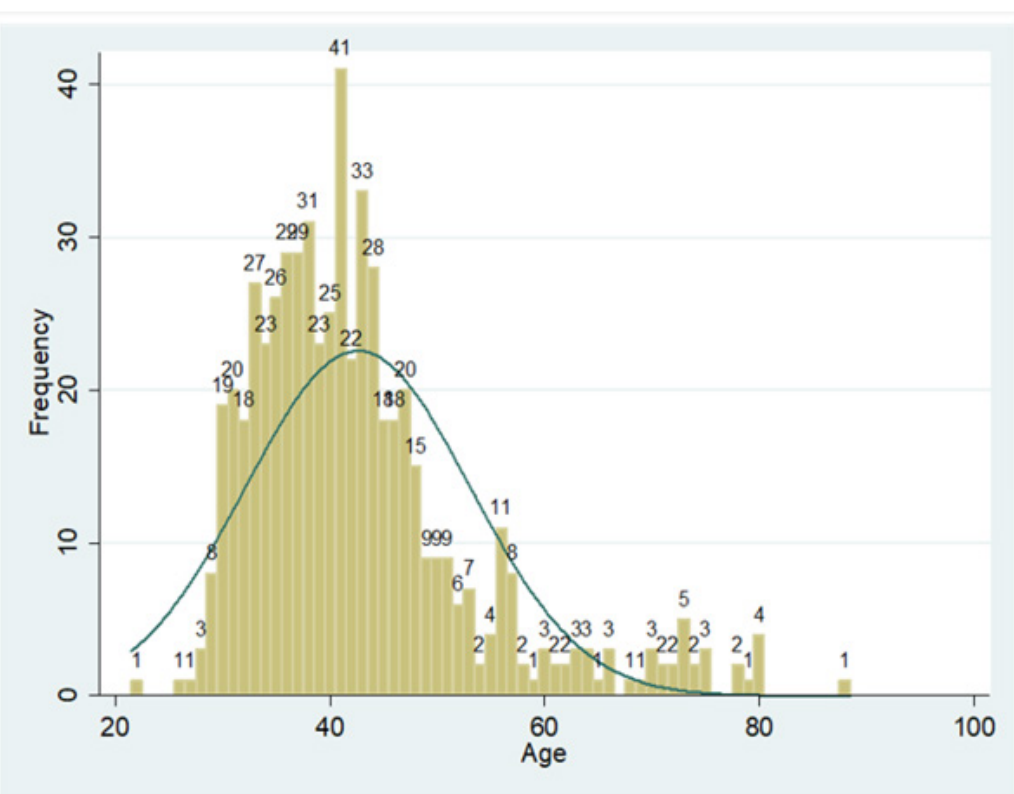

Figure 1: Chronic Hepatitis B virus (HBV) (N=593) by age group (years).

Data were extracted from initial visits to 593 patients with chronic HBV who patients that were assessed during the study period. All the cases were strictly treated in AFH hospital, Fifty-nine percent (352) of the patients were male. The mean age of the study population was 43 years (SD: 10.44), not statistically different from females with the mean age of (43 years SD: 10.70). Eighty-five percent (270) of participants were between 30 and 40 years old (Figure 1). Of the total, $0.5 \%$ were smokers, alcoholics consumed (1\%), hypertensives (5\%), diabetics (6\%), and had a familial history of hepatitis B (24\%). Family history of hepatocellular carcinoma (HCC) was present in (2\%) (Table 1).

\section{Viral hepatitis profile}

The initial cohort included 606 patients. Thirteen patients (2\%) had anti-HBs and anti-HBc indicated HBV immunity due to previous exposure and were therefore excluded from the final analysis. Eighty-eight percent of patients (509) had detectable HBV DNA ( $>10 \mathrm{IU} / \mathrm{ml}$ ). The median of HBV DNA level of the study population was $1239 \mathrm{IU} / \mathrm{ml}$ (QIC: 172-9324). Males had a greater median HBV DNA concentration (2046 IU/ml) than females (459 IU/ml). Ninety-four percent of patients (545) had HBeAg-negative chronic HBV. The median HBV DNA level for HBeAg- negative chronic HBV patients was $339 \mathrm{IU} / \mathrm{ml}$ (IQR: 33.5-3366). Ten percent (57) patients with HBeAg-negative chronic HBV were considered to have had a high viral load (HBV DNA > $2000 \mathrm{IU} / \mathrm{mL}$ ). Six percent of chronic HBV patients (35) were HBeAg-positive. The median of HBV DNA level in these patients with $\mathrm{HBeAg}$ positive chronic hepatitis B was 1,884,847 IU/ml (IQR 81662-486924145). Twenty-nine (83\%) of chronic HBV HBeAg-positive patients with chronic hepatitis B had a high viral load (HBV DNA > 20,000 IU/ml) (Figure 2).

Table 2: Chronic hepatitis B virus (HBV) ultrasound profile of cohort of patients, Oman, 2009-2019.

\begin{tabular}{|c|c|c|c|}
\hline Ultrasound abnormality & Male, $\mathbf{n = 3 4 5}(\mathbf{\%})$ & Female, $\mathbf{n = 2 3 5}(\mathbf{\%})$ & Total population, $\mathbf{n = 5 8 0}(\mathbf{\%})$ \\
\hline Liver & \multicolumn{3}{|c|}{} \\
\hline Yes & $117(34)$ & $48(20)$ & $165(29)$ \\
\hline No & $180(53)$ & $153(15)$ & $333(57)$ \\
\hline
\end{tabular}




\begin{tabular}{|c|c|c|c|}
\hline Not done & $48(13)$ & $34(15)$ & $82(14)$ \\
\hline Spleen & \multicolumn{3}{|c|}{} \\
\hline Yes & $13(4)$ & $2(1)$ & $15(3)$ \\
\hline No & $276(80)$ & $201(86)$ & $477(82)$ \\
\hline Not done & $56(16)$ & $32(14)$ & $88(15)$ \\
\hline
\end{tabular}

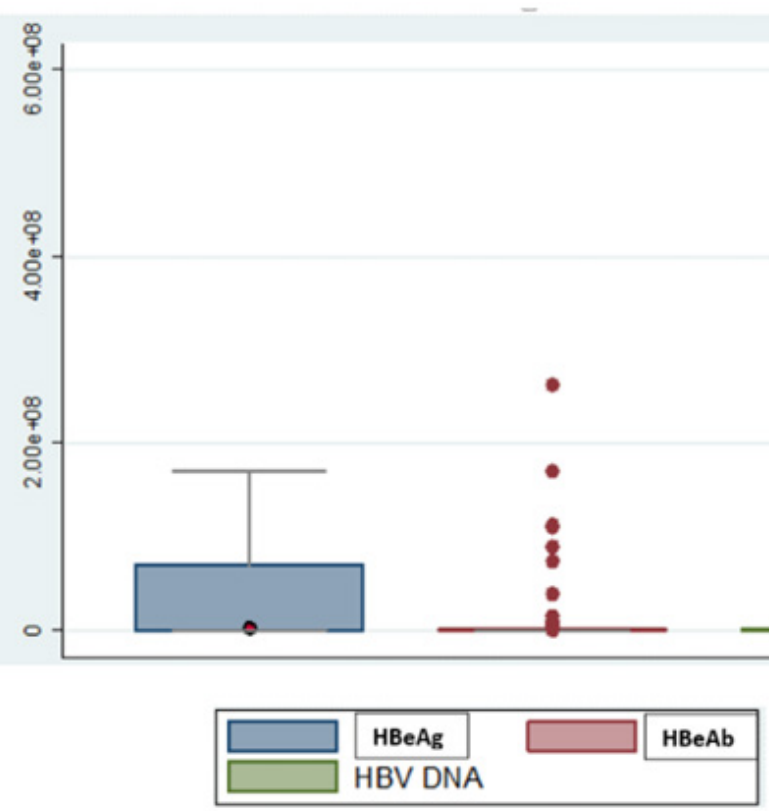

Figure 2: Whisker plot of Viral HBV DNA, HBeAg and HBeAb level per $1000 \mathrm{IU}$.

\section{Liver chemistry test abnormalities}

Twenty-nine percent (167) of patients had high ALT ( $\geq 40$ IU/ $\mathrm{ml}$ ), while 14 percent (80) had high AST ( $\geq 40 \mathrm{IU} / \mathrm{ml}$ ). The mean ALT levels for males $(55.25 \mathrm{IU} / \mathrm{ml})$ were not significantly different from that for females ( $51.45 \mathrm{IU} / \mathrm{ml})$. Although the mean AST level for males were significantly higher $(75.80 \mathrm{IU} / \mathrm{ml})$ than for females (39.26 IU/ml), these differences were not clinically significant. The AST and ALT mean was deflected to the right because of numerous outliers.

\section{Radiological abnormalities}

During the initial consultation, 28\% (165) of patients exhibited liver abnormalities detected by liver ultrasonography. This included hepatomegaly, altered liver echotexture, fatty liver and radiological characteristics of liver cirrhosis. Fifteen patients (3\%) had splenomegaly, indicating portal hypertension (Table 2).

\section{Treatment status}

Eighty-five percent $(492 / 580)$ of the patients were treatment naïve. Of the $15 \%$ (88) treated patients, $9 \%$ used tenofovir, $4.3 \%$ used entercavir, $1 \%$ used adenovirus and $0.7 \%$ used lamuvidin.

\section{Discussion}

HBV infection is still a major concern in Oman. The mean age of the patients in this study was 43 years (SD: 10.44) and the median age was 41 years (IQR: 36-46). The majority of the patients were between 30 and 40 years of age (55\%) signifying that these patients had missed the immunization program, and as such did not receive the birth dose (within 24 hours) as this was introduced back in 2008 [6] or were born to HBV infected mothers. Another factor that could have contributed to a higher rate of infection among this group is the length of time the follow-up vaccination campaigns took to cover the entire country, thus increasing the risk of unvaccinated children contracting the infection from infected family members [10]. The Centers for Disease Control and Prevention (CDC, USA) recommended that the screening of pregnant women for HBV is the standard of care, regardless of previous testing or vaccination [11]. This screening would identify patients that might require treatment as well as infants who require prophylaxis, and other individuals who are in contact with infected people and who would also benefit from testing, counselling, vaccination and therapy, if needed.

Patients in the current study (mean age 43 years) were relatively young. In a study from neighbouring Saudi Arabia the mean age, among admitted patients was (46.9 \pm 14.3 years) [12], however, in another study from Pakistan the mean age in a tertiary hospital 7 was (29.86 years, SD: 13.68). The young age of the Pakistani study might be due to the strength of the country-based screening program [13]. The current study demonstrates a male majority (59\%), displaying similar results to another hospital- 
based retrospective study of 5 years at a tertiary level hospital in Saudi Arabia that showed a $60 \%$ prevalence in males. Similarly, a prevalence of $69.23 \%$ among men was recorded in Kerala, India. Further studies in Pakistan found a male prevalence of $79.5 \%$ and $68.15 \%$, respectively [14,15].

The prevalence of chronic HBeAg-positive in the current study is similar to a prospective cohort study amongst 1158 Native Americans throughout Alaska who were tested serially for HBeAg for a median of 20.5 years [16]. However, the prevalence of HBeAg-positive in our study, although high, is much lower than in other countries. In a study from from Nigeria, $19.2 \%$ of screened chronic HBV individuals were found to be HBeAg-positive [17]. Furthermore, a number of studies have shown that HBeAg-positive chronic hepatitis B tend to have high levels of HBV DNA that were associated with increased risk of cirrhosis and HCC [18-20]. In this study, 29\% of HBeAg-positive patients had a high HBV DNA with a similar potential implication on prognosis. The majority of the patients were HBeAg-negative with low HBV DNA. This is consistent with previous studies from other parts of the world that have demonstrated low levels of HBV DNA in low level of HBVDNA in HBeAg-negative chronic hepatitis B patients [21]. Those patients who are HBeAg-negative and have low HBV DNA are at lower risk of progression to cirrhosis, or HCC [21].

Fifty-seven $(11 \%)$ of the patients who are HBeAg-negative had high viral load (> $2000 \mathrm{IU} / \mathrm{ml}$ ). This high level of HBV DNA among HBe-Ag negative patients that could be attributed to the presence of pre-core and core mutations, may render them vulnerable to develop advanced hepatic fibrosis [22,23]. Nearly one-third of our cohort had a high ALT level of $\geq 40 \mathrm{IU} / \mathrm{ml}$. Historically, the upper limit of normal (ULN) for ALT in males and females was 40IU/ ml. Later studies evaluate the ULN for ALT in both genders among healthy particpants after excluding common cause of elevated transaminases such as non-alcoholic steatohepatitis (NASH), alcohol consumption and chronic HCV infection. The current ULN for ALT in adult men is $30 \mathrm{IU} / \mathrm{ml}$ and $19 \mathrm{IU} / \mathrm{ml}$ in women [24].

Elevated transaminases are used by all international guidelines $[25,26]$ to assess disease activity and therefore is an indication for treatment in addition to other indices. A minimum of two times ULN is required for treatment following exclusion of other causes of transaminitis $[25,26]$. A recent study, looking at a large number of patients (2991) with chronic HBV and correlating ALT level with liver histology concluded that an ALT level less than twice ULN is associated with a low probability of significant inflammation [27].

\section{Study limitation}

The design of our study predisposes to a number of limitations. First, secondary data were obtained. Thus, the integrity of the results is dependent upon the accuracy and integrity of the data. For approximately $8 \%$ of the patients, there was initially no information on HBV DNA. Secondly, we did not collect information on risk factors associated with acquiring hepatitis B infection.
Finally, the clinical data were not collected.

\section{Conclusion}

This study forms the basis of new research into chronic HBV infection in Oman. It indicates that that the introduction of childhood vaccination had significantly impacted the rate of HBV infections in Oman as most of infected patients are among males. Most of the patients were HBeAg-negative chronic hepatitis HBV patients with low HBV DNA and required no treatment but longterm follow-up. Further studies are warranted and could include case-control studies assessing risk factors associated with cirrhosis and/or HCC.

\section{Author Contributions}

KA, STA, GS, AA, BRK, SA, ES, HO and AA conceptualized the project and conducted initial background research, STA, OM and KA planned and conducted the formal analysis and validation, STA, OM and KA interpreted the results, STA led the writing (original draft and editing) of the manuscript, and STA, KA and OM supervised the project. All authors approved the final article.

\section{Acknowledgement}

The authors wish to acknowledge all the participants who were instrumental in the development of the manuscript namely Mamoun Elsheikh and Magda Al Wahabi.

\section{Conflicting Interest}

The authors declared no potential conflicts of interest with respect to the research, authorship, and/or publication of this article.

\section{References}

1. (2021) Interim guidance for country validation of viral hepatitis elimination

2. (2021) Global progress report on HIV, viral hepatitis and sexually transmitted infections.

3. Jefferies M, Rauff B, Rashid H, Lam T, Rafiq S (2018) Update on global epidemiology of viral hepatitis and preventive strategies. World J Clin Cases 6: 589-599.

4. Al Awaidy S, Remon Abu-Elyazeed R, Al Hosani H, Al Mulla A, Al Busaiedy S, et al. (2006) Sero-epidemiology of hepatitis B infection in pregnant women in Oman, Qatar and the United Arab Emirates. J Infect 52(3): 202-206.

5. (2020) Coalition for global hepatitis Elimination

6. Al Awaidy ST, Bawikar SP, Al Busaidy SS, Al Mahrouqi S, Al Baqlani, et al. (2013) Progress toward elimination of hepatitis B virus transmission in Oman: impact of hepatitis B vaccination. The American journal of tropical medicine and hygiene 89(4): 811-815.

7. Al Baqlani SA, Sy BT, Ratsch BA, Khalid Al Naamani, Salah Al Awaidy, et al. (2014) Molecular Epidemiology and Genotyping of Hepatitis B Virus of HBsAgPositive Patients in Oman. PLoS One 9(5): e97759.

8. Al-Naamani K, Al-Maqbali A, Al-Sinani S (2013) Characteristics of hepatitis B infection in a sample of Omani patients. Sultan Qaboos Univ Med J 13: 380-385.

9. Oliveira JPR, de Franca EVC, de Farias Brito HL, Brito HL, Nascimento TV, et al. (2016) ADVANCED LIVER INJURY IN PATIENTS WITH CHRONIC HEPATITIS B AND VIRAL LOAD BELOW 2,000 IU/mL. Rev Inst Med Trop Sao Paulo 58: 65-65. 
10. Villa E, Fattovich G, Mauro A, Pasino M (2011) Natural history of chronic HBV infection: special emphasis on the prognostic implications of the inactive carrier state versus chronic hepatitis. Digest Liver Dis 43(Suppl 1): S8-14.

11. Eric E Mast, Harold S Margolis, Anthony E, Brink EW, Goldstein ST, et al. (2005) A comprehensive immunization strategy to eliminate transmission of hepatitis B virus infection in the United States: recommendations of the Advisory Committee on Immunization Practices (ACIP) part 1: immunization of infants, children, and adolescents. MMWR Recomm Rep 54:1-31.

12. Sanai FM, Alghamdi H, Alswat KA, Mohammed A Babatin, Mona H Ismail, et al. (2019) Greater prevalence of comorbidities with increasing age: Cross-sectional analysis of chronic hepatitis B patients in Saudi Arabia. Saudi J Gastroenterol 25: 194-200.

13. Butt N, Ali Khan M, Haleem F, Butt S, Reema S, et al. (2019) Epidemiology, Clinical Characteristics, and Management Status of Hepatitis B: A Crosssectional Study in a Tertiary Care Hospital at Karachi, Pakistan. Cureus 11(1): e3880.

14. Baig S (2009) Gender disparity in infections of Hepatitis B virus. J Coll Physicians Surg Pak 19: 598-600.

15. Fawad Khan, Sulaiman Shams, Qureshi I, Muhmmad Israr, Hayat Khan, et al. (2011) Hepatitis B virus infection among different sex and age groups in Pakistani Punjab. Virol J 8: 225.

16. Livingston SE, Simonetti JP, Bulkow LR, Homan CE, Snowball MM, et al. (2007) Clearance of Hepatitis B e Antigen in Patients With Chronic Hepatitis B and Genotypes A, B, C, D, and F. Gastroenterology 133: 14521457

17. Forbi JC, Iperepolu OH, Zungwe T, Agwale SM (2012) Prevalence of hepatitis B e antigen in chronic HBV carriers in North-central Nigeria. J Health Popul Nutr 30(4): 377-382.

18. Henry Lik-Yuen Chan, Chi-Hang Tse, Frankie Mo, Jane Koh, Vincent WaiSun Wong, et al. (2008) High viral load and hepatitis B virus subgenotype ce are associated with increased risk of hepatocellular carcinoma. J Clin Oncol 26: 177-182.

19. HJ Yuan, MF Yuen, D Ka Ho Wong, ESablon, CL Lai (2005) The relationship between HBV-DNA levels and cirrhosis-related complications in Chinese with chronic hepatitis B. J Viral Hepat 12: 373-379.

20. Iloeje UH, Yang HI, Su J, Jen CL, You SL, et al. (2006) Risk Evaluation of Viral Load Elevation and Associated Liver Disease/Cancer-In HBV (the REVEAL-HBV) Study Group. Predicting cirrhosis risk based on the level of circulating hepatitis B viral load. Gastroenterology 130(3): 678-686.

21. Chen CJ, Yang HI, Iloeje UH (2009) Hepatitis B virus DNA levels and outcomes in chronic hepatitis B. Hepatology 49: S72-84.

22. Sana Irfan, Mahua Das Gupta, NP Sahu, Zulfi quar Ali Bhuttoo, Poonam Kumari (2019) Experience with Hepatitis B Viral load Testing in Jharkhand. Arch Hepat Res 5: 009-016.

23. Yun Liao, Xin Hu, Jie Chen, Cai B, Tang J, et al. (2012) Precore mutation of hepatitis B virus may contribute to hepatocellular carcinoma risk: evidence from an updated meta-analysis. PloS one 7: e38394-e38394.

24. Schwimmer JB, Dunn W, Norman GJ, Pardee PE, Middleton MS, et al. (2010) Safety study: Alanine aminotransferase cut off values are set too high for reliable detection of pediatric chronic liver disease. Gastroenterology 138(4): 1357-1364.

25. European Association for the Study of the Liver (2017) Clinical Practice Guidelines on the management of hepatitis B virus infection. J Hepatol 67(2): 370-398.

26. Terrault NA, Lok ASF, McMahon BJ, Chang KM, Hwang JP, et al. (2018) Update on prevention, diagnosis, and treatment of chronic hepatitis B: AASLD 2018 hepatitis B guidance. Hepatology 67(4): 1560-1599.

27. Sonneveld MJ, Brouwer WP, Hansen BE, Chan HL, Piratvisuth T, et al. (2020) SONIC-B Study Group. Very low probability of significant liver inflammation in chronic hepatitis B patients with low ALT levels in the absence of liver fibrosis. Aliment Pharmacol Ther 52(8): 1399-1406. 